\title{
Solving the puzzle of eutectic compositions with 'Miracle glasses'
}

A. R. YAVARI

Nature Materials 4, 2-3 (2005).

In this correspondence piece, the reference list was numbered incorrectly. It should have appeared as listed below:

1. Miracle, D. B. A structural model for metallic glasses. Nature Mater. 3, 697-702 (2004).

2. Stockdale, D. Proc. Roy. Soc. A 152, 81 (1935).

3. Hume-Rothery, W. \& Anderson, E. Eutectic compositions and liquid immiscibility in certain binary alloys. Phil. Mag. 5, 383-405 (1960),

4. Hanson, M. The Constitution of Binary Alloys 2nd edn (McGraw-Hill, 1958).

5. Frank, F. C. Proc. Roy. Soc. A 215, 43 (1952).

6. Yavari, A. R. \& Inoue, A. Volume effects in bulk metallic glass formation. Mater. Res. Soc. 554, 21-30 (1999).

7. Yavari, A. R. Small volume change on melting as new criterion for easy glass formation. Phys. Lett. A 95, 165-168 (1983).

8. Miracle, D. B., Sanders, W. S. \& Senkov, O. N. The influence of efficient atomic packing on the constitution of metallic glasses. Phil. Mag. A 83, 2409-2428 (2003). 